\title{
Economic evaluation of outpatients with type 2 diabetes mellitus assisted by a pharmaceutical care service
}

\author{
Avaliação econômica de pacientes ambulatoriais \\ portadores de diabetes melito tipo 2 assistidos \\ por um serviço de atenção farmacêutica
}

Anna Paula de Sá Borges', Camilo Molino Guidoni', Osvaldo de Freitas' ', Leonardo Régis Leira Pereira'

${ }^{1}$ Pharmaceutical Assistance and Clinical Pharmacy Research Center (CPAFF), Department of Pharmaceutical Sciences, Faculdade de Ciências Farmacêuticas de Ribeirão Preto, Universidade de São Paulo (FCFRP-USP), Ribeirão Preto, SP, Brazil

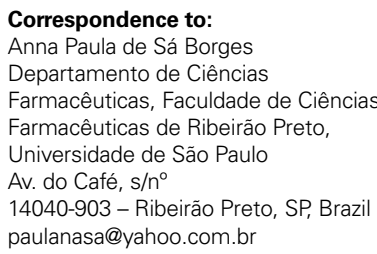

Received on 21/Jan/2011 Accepted on 24/Nov/2011

\begin{abstract}
Objective: To analyze the costs related to visits and drug prescription in outpatients with type 2 diabetes mellitus assisted by a pharmaceutical care service. Subjects and methods: A prospective and experimental study was carried out. Seventy one patients were divided into two groups: control and pharmaceutical care. Patients in the pharmaceutical care group were followed up monthly by a single clinical pharmacist. Results: The pharmaceutical care group had a statistically significant reduction in costs of metformin and emergency department visits, and increased costs with their family physicians. On the other hand, the control group had a statistically significant increase of $21.3 \%$ in the general costs of treatment and visits. Conclusion: The pharmaceutical care group maintained the same costs related to drugs and visits, while the control group showed a significant increase in general costs. Arq Bras Endocrinol Metab. 2011;55(9):686-91

Keywords

Unified Healthcare System; diabetes mellitus; healthcare costs; pharmaceutical care; pharmacoeconomics
\end{abstract}

\section{RESUMO}

Objetivo: Analisar os custos relacionados a medicamentos e consultas em pacientes portadores de diabetes melito tipo 2 acompanhados por um programa de atenção farmacêutica. Sujeitos e métodos: Estudo prospectivo e experimental foi realizado em 71 pacientes, os quais foram divididos em dois grupos: atenção farmacêutica e controle. Os pacientes do grupo atenção farmacêutica foram acompanhados mensalmente por um farmacêutico clínico. Resultados: O grupo atenção farmacêutica apresentou redução estatisticamente significativa no custo da metformina e nas visitas de pronto atendimento e aumento no custo das consultas de atenção primária. Por outro lado, o grupo controle apresentou elevação estatisticamente significativa nos custos gerais de tratamento farmacológico e nas consultas em geral na ordem de $21,3 \%$. Conclusão: $O$ grupo atenção farmacêutica apresentou manutenção dos custos relacionados a consultas e medicamentos, enquanto o grupo controle apresentou aumento destes. Arq Bras Endocrinol Metab. 2011;55(9):686-91

\section{Descritores}

Sistema Único de Saúde; diabetes melito; custos de cuidados de saúde; atenção farmacêutica; farmacoeconomia

\section{INTRODUCTION}

$\mathrm{T}$ he estimated prevalence of diabetes mellitus (DM) in the world population was $6.6 \%$ in 2010 , and this number will increase to $7.8 \%$ by 2030 (1). This prevalence is similar to that of the Brazilian population. However, it is known that this number is underestimated because
$20.0 \%$ to $40.0 \%$ of the population have undiagnosed diabetes $(2-5)$.

$\mathrm{DM}$ is a non-transmissible chronic disease with high prevalence and difficult control, mainly because the patient needs to follow a restricted diet. If non-pharmacological treatment does not lead to acceptable glycemic control, care of the disease must be completed by 
pharmacological treatment. However, according to the World Health Organization, only $50.0 \%$ of patients in developed countries comply with drug treatment $(6,7)$. In addition, the National Health and Nutrition Examination Survey reported that only $37.0 \%$ of patients with DM have adequate disease control (8).

Therefore, as the drug plays a central role in the treatment of diabetes, the presence of the pharmacist becomes essential for monitoring and managing the disease. Thus, this professional may use the pharmaceutical care (PC) as a tool to care for these patients. This practice involves direct interaction between the pharmacist and the patient, with responsible provision of drug therapy in order to achieve definitive outcomes that improve a patient's quality of life and promote disease management (9). It is important to emphasize that literature is mainly based on the clinical impact of pharmaceutical care in the management of diabetes, but studies demonstrating the economic impact of this practice are still scarce (10-12).

Healthcare expenditure on DM is estimated to account for $11.6 \%$ of the total world healthcare expenditure in 2010 . DM consumes from $5.0 \%$ to $13.0 \%$ of annual healthcare budgets. Estimated global healthcare expenditure to treat and prevent DM and its complications are expected to total at least USD 376 billion in 2010, and USD 490 billion by 2030 (1).

Given the number of patients with DM and metabolic abnormalities in Brazil, and the medical costs associated with these conditions, strategies for improving diabetes management seem necessary. According to the International Diabetes Federation, this economic burden can be reduced by implementing many inexpensive, easy-to-use interventions, most of which are cost-effective or cost-saving, even in the poorest countries. Nonetheless, these interventions are not widely used in low- and middle-income countries (1).

The objective of this study was to analyze the costs related to the visits to the family physician, specially qualified professional and emergency visits, and to drugs prescription in type 2 diabetes mellitus (DM2) outpatients assisted by a pharmaceutical care service.

\section{SUBJECTS AND METHODS}

\section{Population of study and intervention program}

Patients of this study were users of the Brazilian Public Health System and periodically seen at the Endocrinology Service of the Health Unit. They were 18-years old or older, and free of hepatotrophic viral diseases or human immunodeficiency virus - acquired immunodeficiency syndrome. A prospective and experimental study was conducted with the patients regularly seen at the Endocrinology Unit (outpatients), and those with poorly controlled diabetes, or noncompliance to prescribed drug treatment, or both, were included.

The outpatients referred to the PC service $(n=71)$ by the physicians were divided into two groups, control group $(n=31)$, which only received standard care (clinical appointments plus drugs) and were followed up only by their medical records, and the PC group $(\mathrm{n}=40)$ which received standard care and PC service. The distribution of patients in these groups was casual. The groups had distinct numbers of patients because, according to the literature, the number of patients that give the treatment up could be as high as $40.0 \%$ in patients followed up by pharmacists $(10,13)$. Thus the PC was larger than the control group.

Results for the PC group were only considered for patients present in the monthly meetings for at least 7 times during the 12 month study (March 2006 to February 2007). Strand and cols. (2004) solved the majority of drug-related problems with four meetings (10). In the PC group, seven patients were excluded: one patient died, one moved to another city, two patients had suspected DM2 and were confirmed as having DMl by a physician, and three were enrolled in another health unit.

The patients in the PC group had standard care and were followed up monthly by a single clinical pharmacist, who collected data and monitored them individually based on the Pharmacistl's Workup of Drug Therapy (PWDT), which contained data on admission (social, demographic, economical and clinical data), follow-up (laboratory data and compliance test), and the therapeutic intervention plan (analysis of the situation and pharmaceutical education according to the patient's problems and necessities) (10). The PC service included questions about the drugs prescribed (name, indication, dosage and possible adverse events), and DM2 (complications and comorbidities), and all data was registered in the pharmaceutical record.

In addition, the pharmacist gave verbal and written orientations related to the control of the disease, compliance with therapeutic treatment, appropriate nutrition and correct use of drugs, including insulin application. The pharmacist also worked in association with other health professionals, and additional interventions were performed, such as adjustment of drug dose, mo- 
dification of the drug therapy (addition or withdrawal), and modification of diet plan, and care of diabetic feet. The patients were also referred to specialists (ophthalmologists, cardiologists and others) when these procedures were required.

All participants in the study signed the Informed Consent form. The research project was approved by the Ethics Committee of this Training and Community Health Center.

\section{Economic analyses}

The economic evaluation compared the PC group versus the control group in relation to the cost of visits to family physicians, specially qualified professionals, and emergency department. In addition, we evaluated the total cost of prescription drugs in relation to the treatment of DM2 (oral antidiabetic drugs and insulin) and the most common comorbidities (antilipidemic, antihypertensive and antiplatelet drugs).

In order to evaluate the costs of drugs, the purchase prices from the Division of Pharmacy of Municipal Health Office of Ribeirao Preto, SP, were used. The costs of the visits to family physicians, specially qualified professionals and emergency department were obtained from the Outpatient Information System of the Brazilian Public Health System.

\section{Statistical analysis}

We used the chi-square test to compare two or more proportions, and Student $t$ test to compare continuous variables with Gaussian distribution. Statistical significance was set at $\mathrm{p}<0.05$. Analyses were performed using the Statistical package for Social Sciences ${ }^{\circledR}$ (SPSS, version $11.5,2002)$.

\section{RESULTS}

Socio-demographic and clinical data of patients in the control and PC group did not show any statistically significant differences (Table 1 ).

We observed a statistically significant reduction in glycosylated hemoglobin (HbAlC) levels of patients in the PC group; even these patients showed a statistically significant reduction in the prescribed dose of metformin. On the other hand, the only significant result in the control group concerning the parameters presented in table 2 was the increase in drug prescription (Table 2).

According to economic analysis, we observed a statistically significant reduction in metformin prescription cost and emergency department visits in the PC group. In addition, this group showed a statistically significant increase in the costs of family physician visits and in the cost of antilipidemic, antiplatelet and antihypertensive drug prescription (Table 3 ). At the end of the study, it

Table 1. Socio-demographic and clinical data of patients with type 2 diabetes mellitus collected at baseline

\begin{tabular}{lcc}
\hline Parameters & $\begin{array}{c}\text { Pharmaceutical } \\
\text { care group }(\mathbf{n = 3 3 )}\end{array}$ & $\begin{array}{c}\text { Control group } \\
(\mathbf{n}=\mathbf{3 1})\end{array}$ \\
\hline Age (years) & $69.4( \pm 8.4)$ & $64.6\left( \pm 11.4^{\star}\right)$ \\
Gender (\%) & & \\
$\quad$ Female & 60.6 & 64.5 \\
$\quad$ Male & 39.4 & 35.5 \\
Length of DM2 diagnosis (years) & $10.8( \pm 6.2)$ & $11.3( \pm 7.2)$ \\
Comorbidities (\%) & & \\
Metabolic syndrome & 78.8 & 71.0 \\
Hypertension & 78.8 & 90.3 \\
Dyslipidemia & 72.7 & 54.8 \\
Obesity & 48.5 & 32.2 \\
\hline
\end{tabular}

${ }^{*} p<0.05$.

Values are presented as means ( \pm standard deviation).

Table 2. Glycosylated hemoglobin, average number of drugs, and mean dose of oral agents and insulin in the pharmaceutical care and control group at baseline and in end of the study

\begin{tabular}{|c|c|c|c|c|c|c|}
\hline \multirow{2}{*}{ Parameters [mean (SD)] } & \multicolumn{3}{|c|}{ Pharmaceutical care group } & \multicolumn{3}{|c|}{ Control group } \\
\hline & Baseline & End of study & Difference $^{a}$ & Baseline & End of study & Difference $^{a}$ \\
\hline Glycosylated hemoglobin (\%) & $8.9(1.4)$ & $7.9(0.8)^{*}$ & $-0.9(1.5)$ & $8.6(1.3)$ & $9.3(1.6)$ & $0.5(1.5)^{\star \star}$ \\
\hline \multicolumn{7}{|l|}{ Average number of drugs } \\
\hline General drug treatment & $4.8(2.1)$ & $5.3(2.3)$ & $0.5(1.8)$ & $4.2(1,7)$ & $4.9(1.6)^{\star}$ & $0.7(1.6)$ \\
\hline Diabetes drug treatment & $1.9(0.8)$ & $1.8(0.8)$ & $-0.2(0.9)$ & $1.8(0.7)$ & $1.7(0.7)$ & $-0.1(0.5)$ \\
\hline Metformin (mg/day) & $2125.0(590.2)$ & $1612.1(1018.3)^{*}$ & $-521.9(1143.7)$ & $1792.4(905.7)$ & $1977.2(884.2)$ & $184.8(1078.4)^{\star *}$ \\
\hline Glibenclamide (mg/day) & $11.0(4.8)$ & $10.7(5.8)$ & $0.6(7.2)$ & $11.5(4.9)$ & $10.6(5.8)$ & $-0.9(8.1)$ \\
\hline Insulin (IU/day) & $28.2(29.5)$ & $25.1(22.2)$ & $-3.1(22.7)$ & $23.3(19.3)$ & $24.3(17.7)$ & $1.1(18.2)$ \\
\hline
\end{tabular}

a Mean difference \pm (standard deviation between) values at the start and end of the study; ${ }^{*} p<0.05$ when comparing values within the group at the start and end of the study; ${ }^{* \star} p<0.05$ when comparing values between Pharmaceutical Care group and Control group; $S D=$ standard deviation. 
Table 3. Monthly costs on drugs and visits for patients in pharmaceutical care and control group at baseline and end of the study, in dollars

\begin{tabular}{|c|c|c|c|c|c|c|}
\hline \multirow{2}{*}{$\begin{array}{l}\text { Parameters (US\$) } \\
\text { [Mean (SD)] }\end{array}$} & \multicolumn{3}{|c|}{ Pharmaceutical care group $(n=33)$} & \multicolumn{3}{|c|}{ Control group $(n=31)$} \\
\hline & Baseline & End of the study & Difference $^{a}$ & Baseline & End of the study & Difference $^{a}$ \\
\hline $\begin{array}{l}\text { General cost of drugs treatment } \\
\text { and visits }\end{array}$ & $11.4(9.7)$ & $11.4(9.1)$ & $-0.003(10.0)$ & $8.9(6.1)$ & $10.8^{\star}(5.8)$ & $1.9(4.9)$ \\
\hline General cost of drugs & $10.2(9.7)$ & $10.0(7.9)$ & $-0.1(10.1)$ & $7.6(6.0)$ & $9.2^{\star}(5.9)$ & $1.6(4.7)$ \\
\hline Cost of oral antidiabetic and insulin & $7.4(8.8)$ & $6.5(7.3)$ & $-0.9(9.7)$ & $5.5(5.7)$ & $5.7(5.6)$ & $0.2(4.2)$ \\
\hline Metformin & $1.4(0.7)$ & $1.1(0.8)^{\star}$ & $-0.4(0.8)$ & $1.0(0.9)^{\star \star}$ & $1.1(0.9)$ & $0.1(0.7)^{\star \star}$ \\
\hline Glibenclamide & $0.5(0.5)$ & $0.5(0.6)$ & $0.0002(0.7)$ & $0.6(0.5)$ & $0.5(0.6)$ & $-0.1(0.6)$ \\
\hline Insulin & $5.5(8.7)$ & $5.0(6.7)$ & $-0.6(9.4)$ & $3.9(5.9)$ & $4.1(5.7)$ & $0.2(4.2)$ \\
\hline $\begin{array}{l}\text { Cost of antilipemic, antiplatelet } \\
\text { and antihypertensive drugs }\end{array}$ & $1.4(1.7)$ & $2.6(2.1)^{\star}$ & $1.1(2.7)$ & $1.7(1.9)$ & $2.7(2.1)^{\star}$ & $1.1(2.8)$ \\
\hline General cost of visits & $1.3(1.9)$ & $1.4(2.1)$ & $0.2(0.7)$ & $1.3(1.4)$ & $1.6(1.2)$ & $0.3(1.8)$ \\
\hline Family physician & $0.2(0.3)$ & $0.5(0.9)^{\star}$ & $0.4(0.7)$ & $0.1(0.2)$ & $0.3(0.3)$ & $0.1(0.3)$ \\
\hline Specially qualified professional & $0.3(0.7)$ & $0.3(0.6)$ & $-0.05(0.3)$ & $0.6(1.2)$ & $0.5(0.8)$ & $-0.05(1.3)$ \\
\hline Emergency department visits & $0.8(1.6)$ & $0.6(1.2)^{*}$ & $-0.2(0.6)$ & $0.6(0.7)$ & $0.8(0.7)$ & $0.3(1.1)^{\star \star}$ \\
\hline
\end{tabular}

${ }^{a}$ Mean difference \pm standard deviation between values at the start and end of the study; ${ }^{*} p<0.05$ when comparing values within the group at the start and end of the study; ${ }^{* \star} p<0.05$ when comparing values between pharmaceutical care group and control group; $S D$ = standard deviation.

was possible to observe a reduction of $1.0 \%$ in the values of HbAlC in the PC group, with the same general cost of drug treatment and visits.

In relation to the control group, there was a statistically significant increase in the total cost of treatment, including drugs and visits (Table 3). Besides, this group had an increase of $0.7 \%$ in $\mathrm{HbAlc}$ levels, and there is an increase in the general cost of drug treatment and visits of $\$ 22.8$.

\section{DISCUSSION}

The Unified Healthcare System has a set of actions to promote health, prevention, diagnosis, treatment, professional training, monitoring and pharmaceutical services, and research for diabetes care. A milestone in diabetes management in Brazil was the National Policy for Diabetes Care which provides drugs and supplies necessary for diabetes control for free. The drugs that are distributed by the public health system for the treatment of DM patients are: insulin and oral hypoglycemic agents, gliburide $5 \mathrm{mg}$ and metformin $500 \mathrm{mg}$ and 850 $\mathrm{mg}$. These drugs are considered essential by the World Health Organization (WHO), and are in the National List of Essential Drugs (14).

However, access to treatment is not enough without patient information and education on the disease. Therefore, the emphasis on basic healthcare occurs by means of clinical protocols, training of health pro- fessionals, pharmaceutical service with free supply of drugs, supplies for self-monitoring of capillary glucose, and patient education (14).

In this study, we evaluated the costs related to visits and drug prescription for the treatment of DM2 in two groups of patients (control versus PC group). The control group showed the lowest costs of drug treatment and visits during period of the study, making it financially feasible, on a superficial analysis of monetary resources for managers, when compared to PC group (US\$ 8.9 versus US\$ 11.4) (Table 3). However, Pharmaceutical Care in the PC group promoted a statistically significant improvement in $\mathrm{HbAlc}$ values (Table 2). Besides, there was a statistically significant reduction in mean dose $(24.6 \%)$ and cost $(25.0 \%)$ of metformin in the PC group (Tables 2 and 3 ). Although patients in the PC group did not reach HbAlc values $(<7.0 \%)$ recommended by the American Diabetes Association $(\mathrm{ADA})$ at the end of the study, the reduction in drug dose was carried out by the medical team with the support of pharmacists in nine patients. In four of these patients, changes were due to improvement in glycemic control; three presented adverse gastrointestinal reactions, and two elderly patients required full insulinization. Thus, changes in metformin dose in these patients significantly influenced the values of the final mean dose.

In addition, the average consumption of drugs in the PC group remained constant during period of the 
study. On the other hand, the control group showed statistically significant increases in HbAlc values, general drug treatment consumption (Table 2), and general cost of drug treatment (Table 3 ).

According to some researchers, the reduction of $\mathrm{HbAlC}$ to $\leq 7.0 \%$ was a $30.0 \%$ decrease in expenditure for long-term health care, and patients with $\mathrm{HbAlc}$ values $\leq 8.0 \%$ have a lower probability of hospitalization (15-17). In the present study, $66.0 \%$ of patients in PC group presented $\mathrm{HbAlC}$ values lower than $8.0 \%$, while in the control group, this proportion was only $33.0 \%$ (data not shown).

In relation to the treatment of comorbidities, we observed a statistically significant increase of costs with antilipidemic, antihypertensive and antiplatelet drugs in the control and PC group, respectively, $58.8 \%$ and $85.7 \%$, at the end of the study (Table 3 ). As previously reported, patients in the PC group were referred to specialists (ophthalmologists, cardiologists and others) as needed, optimizing the care of comorbidities and complications of diabetes.

In relation to the visits, the $\mathrm{PC}$ group showed a statistically significant increase in family physician visits, and statistically significant reduction of emergency department visits, which is the most expensive visits of this study (Table 3 ). These findings show that the PC service contributed to readjusting the levels of attention in the Brazilian Public Health System in the PC group.

Therefore, at the end of the study, PC contributed to maintaining the same general costs of drug treatment and visits in the PC group. On the other hand, the control group had statistically significant increase of $21.3 \%$ in this cost at the end of the study. Consequently, the pharmacist, getting integrated into the healthcare team, plays an essential role in patient pharmacotherapy, making suggestions to medical professional about drug therapy such as dose adjustments, adding or withdrawing $\operatorname{drug}(\mathrm{s})$, or both, among other actions $(12,18$ 21). Thus, pharmacotherapeutic monitoring conducted by the pharmacist in the PC group during the period of the study contributed to encourage patient adherence to treatment, identified drug-related problems, such as adverse drug reactions, and promoted rational drug use. All these pharmaceutical actions together with the actions of the healthcare team improved pharmacological therapy, wich resulted in better glycaemic control in patients with DM2. Besides, these actions also optimized the cost of pharmacological treatment.
It is important to emphasize that there is a considerable number of studies in the literature showing evidence of the impact of pharmaceutical care in improving clinical parameters such as fasting glucose, $\mathrm{HbAlc}$, blood pressure and lipid profile. However, there are few studies in the literature that relate the benefits of pharmaceutical care practice with its real economic impact.

The results of this study contribute to the body of information in the literature that supports the expanded role of the pharmacist to improve clinical and economic outcomes in patients with DM2, showing that the final cost was similar in both groups, but clinical outcomes were better in the PC group, providing cost-effective care. However, it is important to emphasize that at beginning of study, the control group showed lower general cost of drug treatment and visits. In addition, there were no changes in general costs during the study in the PC group.

The limitations of this study are related to the sample size, which is considered small when compared with other studies $(22,23)$. Additionally, patient selection was not random, and the type of the intervention did not enable blinding of the pharmacist. In addition, the period of the study prevented the evaluation of the incidence of micro and macrovascular complications, an important factor to be considered in pharmacoeconomic studies.

\section{CONCLUSION}

Patients in the control group showed an increase in $\mathrm{HbAlc}$ values and a statistically significant increase in total costs of visits and drugs. On the order hand, the practice of pharmaceutical care in PC group optimized pharmacological therapy, contributed to a statistically significant reduction in HbAlc values, and economically optimized costs in visits and drugs.

Acknowledgements: the study was supported by the CAPES (Coordenação de Aperfeiçoamento de Pessoal de Nível Superior) and $\mathrm{CNPq}$ (Conselho Nacional de Desenvolvimento Tecnológico e Científico). The authors would like to thank all patients who participated in this study.

Disclosure: no potential conflict of interest relevant to this article was reported.

\section{REFERENCES}

1. International Diabetes Federation. Diabetes Atlas. 4th ed. Brussels: International Diabetes Federation, 2009. Available at: http:// 
www.diabetesatlas.org/content/diabetes. Accessed: Jan 19, 2011.

2. American Diabetes Association. Diabetes 1996 Vital Statistics. American Diabetes Association: Alexandria, VA, 1996.

3. Centers for Disease Control and Prevention. National Diabetes Fact Sheet: national estimates and general information on diabetes and prediabetes in the United States, 2011. Atlanta, GA: U.S. Department of Health and Human Services, Centers for Disease Control and Prevention, 2011. Available at: http://diabetes.niddk. nih.gov/dm/pubs/statistics/\#Diagnosed20.

4. Lyra R, Silva RS, Montenegro Jr RM, Matos MVC, Cezar NJB, Silva LM. Prevalência de diabetes melito e fatores associados em população urbana adulta de baixa escolaridade e renda do sertão nordestino brasileiro. Arq Bras Endocrinol Metab. 2010;54(6):560-6.

5. Centers for Disease Control and Prevention. National diabetes fact sheet: general information and national estimates on diabetes in the United States, 2007. Atlanta, GA: U.S. Department of Health and Human Services, Centers for Disease Control and Prevention, 2008.

6. Nichols-English G, Poirier S. Optimizing adherence to pharmaceutical care plans. J Am Pharm Assoc. 2000;40(4):475-85.

7. World Health Organization. Adherence to long-term therapies: evidence for action. Geneva: WHO publications; 2003. p. 211. Available at: http://www.who.int/chp/knowledge/publications/ adherence_full_report.pdf/

8. Saydah S, Fradkin J, Cowie CC. Poor control of risk factors for vascular disease among adults with previously diagnosed diabetes. JAMA. 2004;291:335-42.

9. Hepler CD, Strand LM. Opportunities and responsibilities in pharmaceutical care. Am J Hosp Pharm. 1990; 47(3):533-43.

10. Strand LM, Cipolle RJ, Morley PC, Frakes MJ. The impact of pharmaceutical care practice on the practitioner and the patient in the ambulatory practice setting: twenty-five years of experience. Curr Pharm Des. 2004;10(31):3987-4001.

11. Ramalho de Oliveira D, Brummel AR, Miller DB. Medication therapy management: 10 years of experience in a large integrated health care system. J Manag Care Pharm. 2010;16(3):185-95.

12. Borges APS, Guidoni CM, Freitas O, Pereira LRL. The pharmaceutical care of patients with type 2 diabetes mellitus. Pharm World Sci. 2010;32(6):730-6. Epub 2010 Aug 24
13. Lyra DP, Kheir N, Abriata JP, da Rocha CE, Dos Santos CB, Pelá IR. Impact of pharmaceutical care interventions in the identification and resolution of drug-related problems and on quality of life in a group of elderly outpatients in Ribeirão Preto (SP), Brazil. Ther Clin Risk Manag. 2007;3(6):989-98.

14. Ministério da Saúde - Brasil. Secretaria de Políticas Públicas. Plano de reorganização da atenção à hipertensão arterial e ao diabetes mellitus. Rev Saúde Pública. 2001;35(06):585-8.

15. Menzin J, Langley-Hawthorne C, Friedman M, Boulanger L, Cavanaugh $R$. Potential short-term economic benefits of improved glycemic control: a managed care perspective. Diabetes Care. 2001;24:51-5.

16. Shetty SS, Secnik K, Oglesby AK. Relationship of glycemic control to total diabetes-related costs for managed care health plan members with type 2 diabetes. J Manag Care Pharm. 2005;11(7):559-64.

17. Oglesby AK, Secnik K, Barron J, Al-Zakwani I, Lage MJ. The association between diabetes related medical costs and glycemic control: a longitudinal analysis. Cost Eff Resour Alloc. 2006;4:1.

18. Fox D, Ried LD, Klein GE, Myers W, Foli K. A medication therapy management program's impact on low-density lipoprotein cholesterol goal attainment in medicare part $D$ patients with diabetes. J Am Pharm Assoc. 2009;49(2):192-9.

19. Posey LM, Tanzi MG. Diabetes care: model for the future of primary care. J Am Pharm Assoc. 2010;50(5):623-6.

20. Wang J, Thomas J, Byrd D, Nola K, Liu J. Status of diabetes care among community pharmacy patients with diabetes: Analysis of the Medical Expenditure Panel Survey. J Am Pharm Assoc. 2010;50(4):478-84.

21. Correr CJ, Pontarolo R, Wiens A, Rossignoli P, Melchiors AC, Radominski $R$, et al. Economic evaluation of pharmacotherapeutic follow-up in type 2 diabetes mellitus patients in community pharmacies. Arq Bras Endocrinol Metabol. 2009;53(7):825-33.

22. Davidson MB, Karlan VJ, HairTL. Effect of a pharmacist-managed diabetes care program in a free medical clinic. Am J Med Qual. 2000;15(4):137-42.

23. Maccord AD. Clinical Impact of a pharmacist-management diabetes mellitus drug therapy management service. Pharmacotherapy. $2006 ; 26(2): 248-53$. 